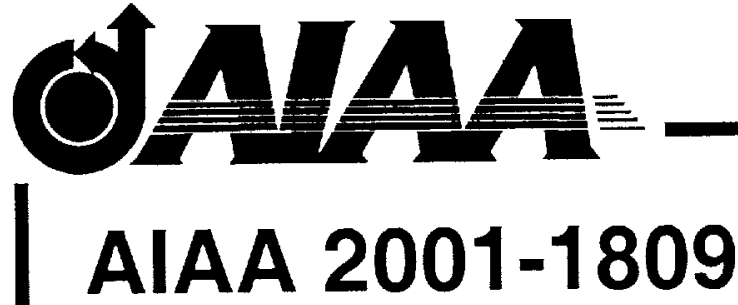 \\ Hyper-X Flight Engine Ground Testing for X-43 Flight Risk Reduction
}

Lawrence D. Huebner, Kenneth E. Rock, Edward G. Ruf and David W. Witte

NASA Langley Research Center

Hampton, VA

Earl H. Andrews, Jr.

Swales Aerospace

Hampton, VA

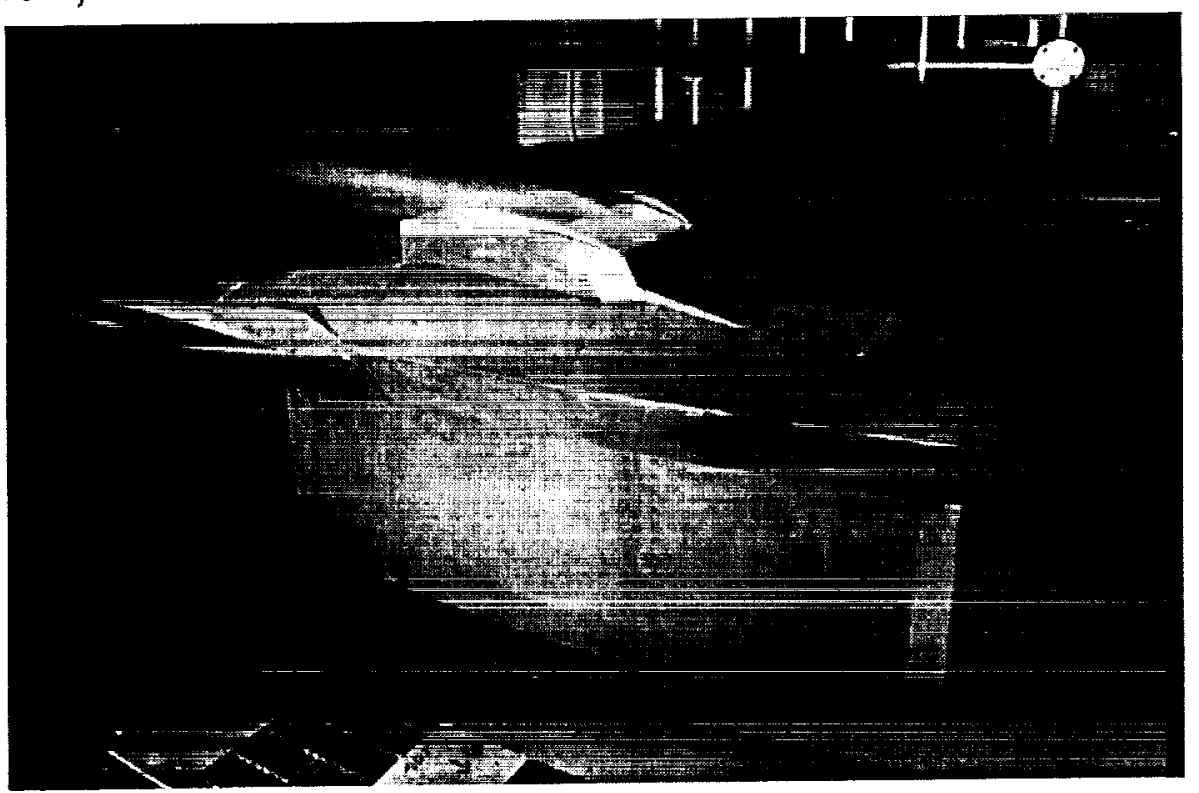

AIAA/NAL-NASDA-ISAS

10th International Space Planes and Hypersonic Systems and Technologies Conference April 24-27, 2001

Kyoto, Japan 
AIAA 2001-1809

\title{
HYPER-X FLIGHT ENGINE GROUND TESTING FOR X-43 FLIGHT RISK REDUCTION
}

\author{
Lawrence D. Huebner*, Kenneth E. Rock ${ }^{\dagger}$, Edward G. Ruf ${ }^{\ddagger}$, and David W. Witte ${ }^{\dagger}$ \\ NASA Langley Research Center \\ Hampton, VA, USA
}

Earl H. Andrews $\$$

Swales Aerospace

Hampton, VA, USA

\begin{abstract}
Airframe-integrated scramjet engine testing has been completed at Mach 7 flight conditions in the NASA Langley 8-Foot High Temperature Tunnel as part of the NASA Hyper-X program. This test provided engine performance and operability data, as well as design and database verification, for the Mach 7 flight tests of the Hyper-X research vehicle (X-43), which will provide the first-ever airframe-integrated scramjet data in flight. The Hyper-X Flight Engine, a duplicate Mach 7 $X-43$ scramjet engine, was mounted on an airframe structure that duplicated the entire three-dimensional propulsion flowpath from the vehicle leading edge to the vehicle trailing edge. This model was also tested to verify and validate the complete flight-like engine system. This paper describes the subsystems that were subjected to flight-like conditions and presents supporting data. The results from this test help to reduce risk for the Mach 7 flights of the X-43.
\end{abstract}

\section{Nomenclature}

8-Ft. HTT NASA Langley 8-Foot High Temperature Tunnel

AETB Alumina-Enhanced Thermal Barrier

AOA, $\alpha$ angle of attack (degrees)

BLA Boeing Lightweight Ablator

$\mathrm{C}_{\mathrm{D}}$ drag coefficient

$C_{L}$ lift coefficient

$\mathrm{C}_{\mathrm{M}}$ pitching moment coefficient

* Aerospace Engineer, Hypersonic Airbreathing Propulsion Branch, Associate Fellow, AIAA

† Aerospace Engineer, Hypersonic Airbreathing Propulsion Branch, Member, AIAA

\# Aerospace Engineer, Hypersonic Airbreathing Propulsion Branch

8 Aerospace Engineer, Assigned to the Hyper-X Program Office, Associate Fellow, AIAA

Copyright $\odot 2001$ by the American Institute of Aeronautics and Astronautics, Inc. No copyright is asserted in the United States under Title 17, U. S. Code. The U. S. Government has a royalty-free license to exercise all rights under the copyright claimed herein for Governmental Purposes. All other rights are reserved by the copyright owner.

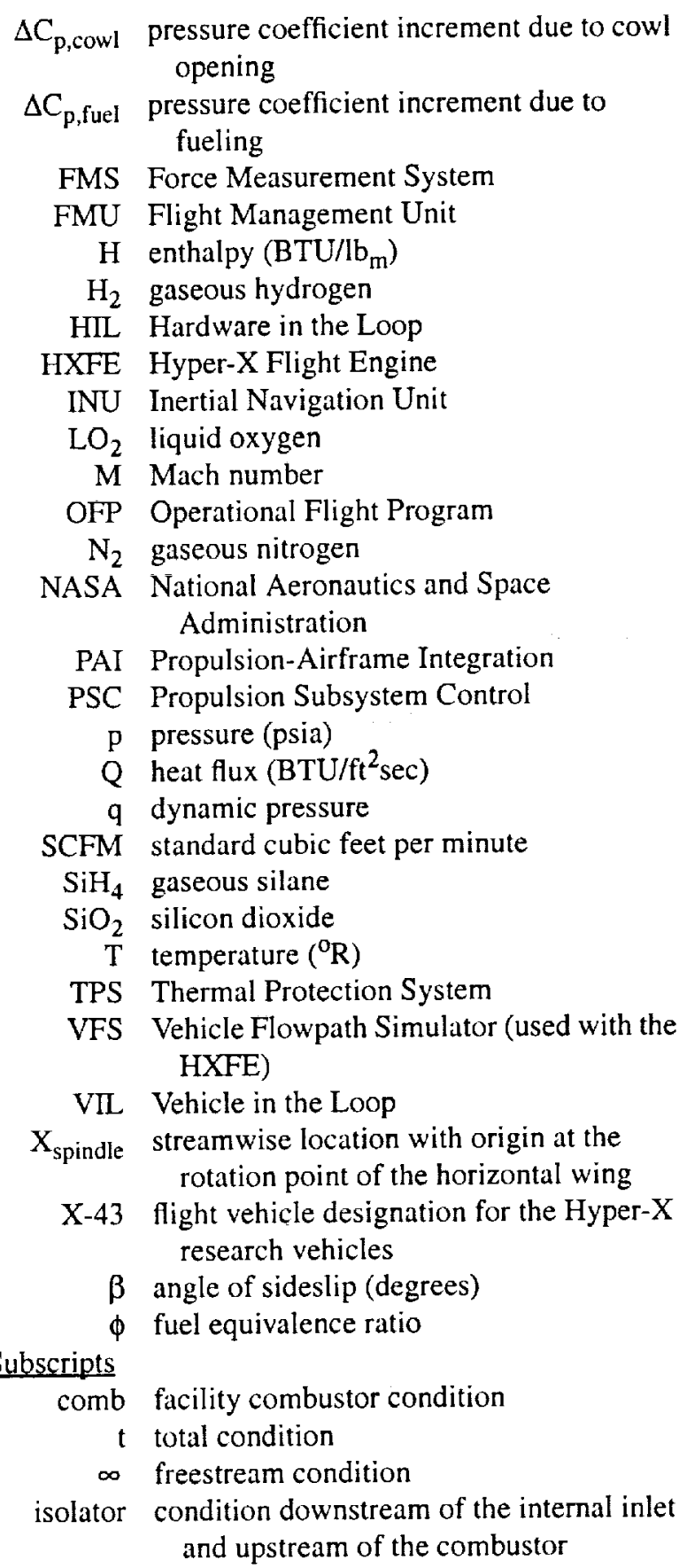




\section{Introduction}

NASA's Hyper-X program will advance technologies for vehicles utilizing hypersonic airbreathing propulsion from the laboratory to the flight environment by obtaining data on a hydrogen-fueled, airframe-integrated, dual-mode supersonic combustion ramjet (scramjet) propulsion system in flight. ${ }^{1}$ These data will provide the first flight validation of analytical and computational techniques and wind-tunnel test techniques used to design and analyze this class of vehicle. The Hyper-X program is jointly conducted by NASA Langley Research Center and NASA Dryden Flight Research Center. The flight-test project phase of the program involves the fabrication and flight testing of three unpiloted, autonomous Hyper- $X$ research vehicles, designated $X-43$. These vehicles are fabricated by a contractor team led by MicroCraft that includes The Boeing Company and GASL, Inc. ${ }^{2}$

The first two X-43 flights will be conducted at Mach 7, with the third flight being conducted at Mach 10. Each engine will be tested at a freestream dynamic pressure of approximately $1000 \mathrm{psf}$. The flights will commence with a captive carry of the Hyper- $X$ launch vehicle (consisting of the $\mathrm{X}-43$ and a modified Pegasus booster) below the wing of a NASA Dryden B-52 aircraft to a Mach number of about 0.6 and an altitude of about $20,000 \mathrm{ft}$. The launch vehicle will then be dropped from the B-52 and will ascend to the planned flight condition at approximately $95,000 \mathrm{ft}$. for the Mach 7 flights and $110,000 \mathrm{ft}$. for the Mach 10 flight where the X-43 will separate from the booster. Once the X-43 has established post-separation, unpowered, controlled flight, the inlet cowl door will open to start the inlet, and five seconds of unfueled tare data will be acquired. Following this, the fuel sequence will commence, resulting in about eight seconds of hydrogen-fueled powered vehicle operation. Once the fuel is depleted and engine operation is complete, unfueled tare data will again be acquired, aerodynamic parameter identification maneuvers will be performed, the inlet door will be closed, and the X-43 will fly a controlled, unpowered, deceleration trajectory until completion of the flight. These 700- to 1000-mile autonomous flights of the X-43 will be flown on a due-west heading in the Western Test Range over the Pacific Ocean off the California coast.

A series of five wind tunnel tests were performed as part of Mach 7 propulsion flowpath verification involving three different engine models in three different facilities. These facilities and engines allowed an integrated test program to be conducted in order to isolate and measure the effects on engine operability and performance caused by such details as geometric scale, dynamic-pressure, and test-gas differences. These differences exist due to test-technique and facility variations; and, the effects of these differences must be accounted for in design and analysis methods when using wind tunnel results as an integral part of the engine and vehicle design. The development of the Mach 7 X-43 engine flowpath and its integration with an airframe are described in greater detail in Reference 3 .

Two of the aforementioned Mach 7 flowpath development tests were performed in the 8-Foot High Temperature Tunnel (8-Ft. HTT) as part of an overall effort to understand the major differences between the preliminary flowpath development databases and the X-43 flight database. ${ }^{4}$ The second of these tests provided the first-ever wind tunnel test of a full-scale, airframe-integrated, scramjet-engine flowpath at simulated flight conditions. The engine, known as the Hyper-X Flight Engine (HXFE), is the only full-width Mach 7 Hyper-X scramjet engine tested prior to the X-43 flights. The Vehicle Flowpath Simulator (VFS) was an airframe structure to which the HXFE was mounted. The VFS represented a geometrically accurate tip-to-tail $\mathrm{X}-43$ propulsion flowpath, including forebody compression surfaces and aftbody expansion that replicates the entire undersurface of the X-43.

The main objectives of the HXFE/VFS test were: (1) to validate the Mach 7 propulsion database and compare the results to other ground tests and correlate the data with the X-43 flight data and (2) to provide important component and systems verification and validation prior to flight. Not only were engine operability and performance data acquired during testing, but unique data were acquired to provide realistic estimates of the aero-propulsive vehicle force and moment increments due to both opening the fullwidth cowl door (prior to engine ignition) and the effects of combustion itself.

This paper focuses on the second of these two objectives. Following a brief discussion of the facility and the model, the components and subsystems that were verified and validated will be presented. Exercising and demonstrating these components and subsystems in a flight-like environment inherently reduces risk associated with the first flight. The paper will conclude with a presentation of some relevant vehicle data that support both the Mach 7 flights and verify key issues that will be addressed in future scramjet-powered vehicle development.

\section{8-Foot High Temperature Tunnel}

The NASA Langley 8-Ft. HTT $^{5}$ has be used to conduct aerothermal loads, aerothermo-structures, highenthalpy aerodynamics, and airbreathing propulsion research. A schematic representation of the 8-Ft. HTT configured for airbreathing engine testing is shown in Figure 1. The facility, capable of testing large 
hypersonic airbreathing propulsion systems at flight enthalpies from Mach 4 to Mach 7, employs a force measurement system (FMS) to acquire longitudinal aero-propulsive loads (axial force, normal force, and pitching moment) of the test articles. The FMS is attached to the facility model elevator carriage, which inserts the model assembly into the test section once the proper flow conditions are established and retracts the model at run completion. This insertion capability allows for the testing of larger models by reducing blockage, improving tunnel starting, reducing transient loads on the model, and increasing safety.

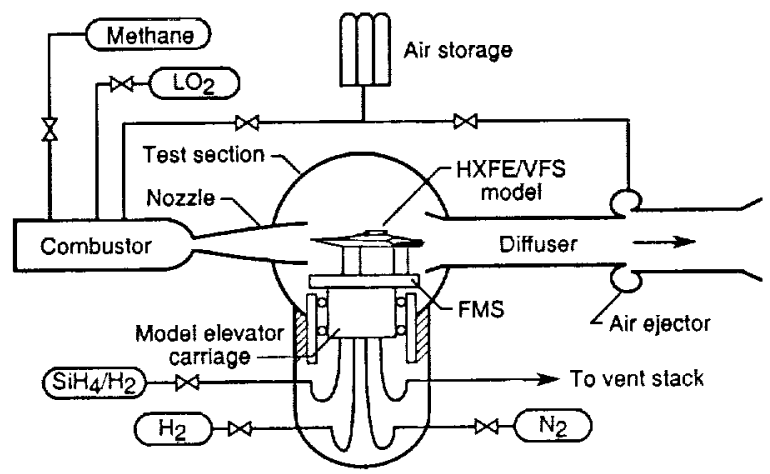

Figure 1. Schematic drawing of the 8-Ft. HTT for aibreathing propulsion testing.

Testing of the HXFE/VFS was performed for three dynamic pressures at, above, and below the nominal Mach 7 X-43 flight condition. The nominal tunnel combustor conditions and resulting simulated air freestream flow parameters are presented in Table 1 . The simulated Mach number, static pressure, and flight simulation conditions are within four percent of those expected for the nominal Mach 7 X-43 flight condition. Reference 4 contains more information about these test conditions.

Table 1: Simulated Freestream Conditions for 8-Ft. ITT IIXFE/VFS Testing and Comparison to Flight

\begin{tabular}{|l|c|c|c|c|}
\hline \multicolumn{1}{|c|}{$\begin{array}{c}\text { Simulation } \\
\text { Case }\end{array}$} & $\begin{array}{c}\text { Tunnel } \\
\text { Low } \mathrm{q}_{\infty}\end{array}$ & $\begin{array}{c}\text { Tunnel } \\
\text { Flight } \\
\mathrm{q}_{\infty}\end{array}$ & $\begin{array}{c}\text { Target } \\
\text { Flight } \\
\text { Point }\end{array}$ & $\begin{array}{c}\text { Tunnel } \\
\text { High } \mathrm{q}_{\infty}\end{array}$ \\
\hline $\mathrm{p}_{\text {comb }}(\mathrm{psig})$ & 1000 & 1585 & Air & 2000 \\
\hline $\mathrm{T}_{\text {comb }}\left({ }^{\circ} \mathrm{R}\right)$ & 3250 & 3350 & 3350 \\
\hline $\mathrm{M}_{\infty}$ & 6.84 & 6.92 & 7.00 & 6.87 \\
\hline $\mathrm{p}_{\infty}(\mathrm{psia})$ & 0.140 & $0.21 \mathrm{I}$ & 0.204 & 0.263 \\
\hline $\mathrm{q}_{\infty}(\mathrm{psf})$ & 647 & 1000 & 1000 & 1230 \\
\hline $\mathrm{T}_{\infty}\left({ }^{\circ} \mathrm{R}\right)$ & 434 & 423 & 408 & 434 \\
\hline $\mathrm{H}_{\mathrm{l}}\left(\mathrm{BTU} / \mathrm{b}_{\mathrm{m}}\right)$ & 1064 & 1052 & 1052 & 1064 \\
\hline
\end{tabular}

\section{HXFE/VFS Model Description}

The HXFE/VFS installation in the 8-Ft. HTT is shown in Figure 2. The HXFE/VFS flowpath is inverted from the flight orientation to facilitate fluid and instrumentation interfaces and to mitigate strut interference on the propulsion flowpath caused by mounting the model to the facility. The model simulates the complete X-43 propulsion flowpath, including vehicle geometry that affects the flow entering the engine inlet or interacting with the nozzle exhaust plume. The pedestal houses the fuel control system and model instrumentation and provides access for internal cavity purging/cooling of the airframe structures and water cooling of engine leading edges. Angle-of-attack (AOA) spacers provided the ability to change model attitude between runs; the nominal angle of attack for the first flight is two degrees. Most of the runs were at this orientation, but the model was also tested at zero and four degrees angle of attack to further examine the design space for which the X-43 pre-flight performance database was generated. Special support brackets provided the ability to vary sideslip angle at the modelto-pedestal interface between zero and three degrees. Configurational details of the HXFE/VFS model are shown in Figure 3. Many of these details are included as part of the verification and validation for flight and will be discussed in subsequent sections.

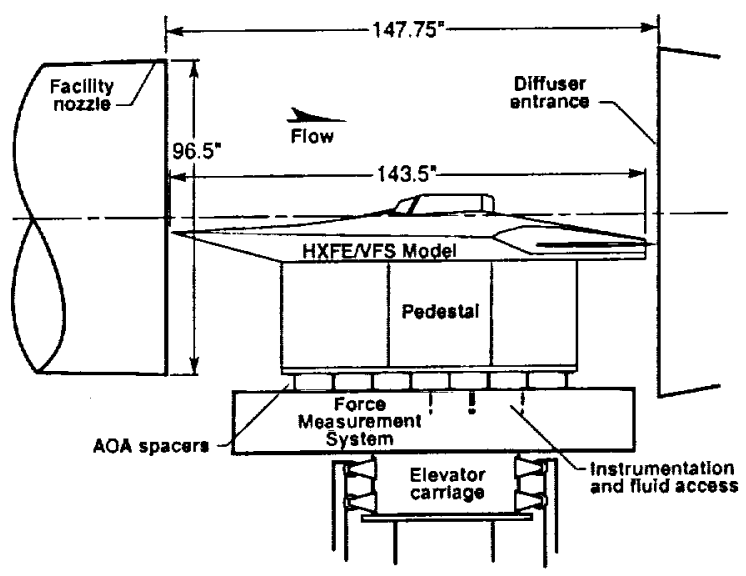

Figure 2. HXFE/VFS installation in the 8-Ft. HTT.

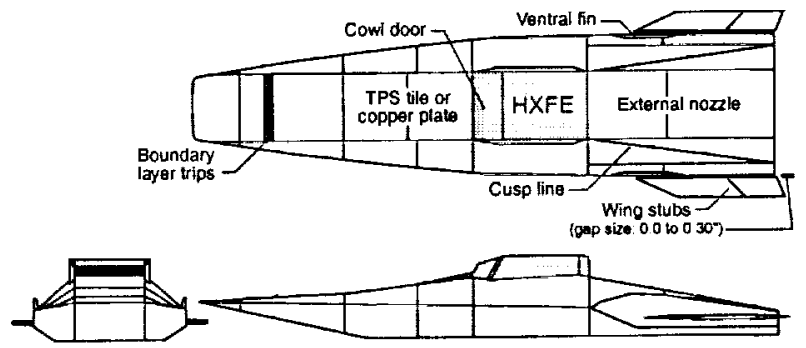

Figure 3. HXFE/VFS configurational details. 
The HXFE (Figure 4) is a flight-spare, Mach 7 Hyper-X scramjet engine that is dedicated to ground testing. Physical attachment of the HXFE to the VFS is identical to attachment of the engine in the $\mathrm{X}-43$ via the six mounting lugs shown. A detailed description of the HXFE/VFS model, instrumentation, and interfaces with the facility are found in Reference 4.

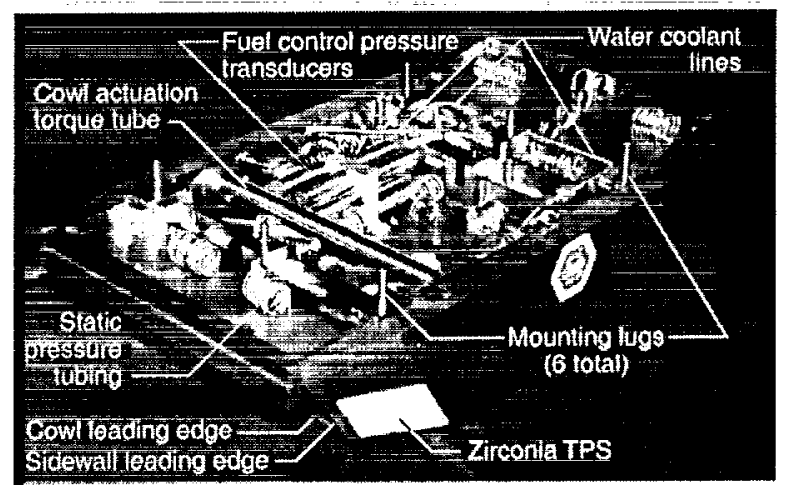

Figure 4. Image of the Mach 7 Hyper-X Flight Engine.

\section{Test Summary}

Fourteen unfueled runs were made with the HXFE/VFS. Six of these runs were used to characterize the inlet flowfield plane via pitot pressure and total temperature rake survey data for the three angles of attack at the target flight dynamic pressure, two dynamic pressures at the target flight angle of attack, and the three boundarylayer trip options (discussed in the next section) at the target flight dynamic pressure and angle of attack. The remaining eight unfueled runs addressed cowl-door actuation and quantification of force and moment increments for the cowl-opening event.

Forty fueled runs were performed to primarily examine engine performance and operability. In addition to preprogrammed fueling-sequence runs, engine control-law development runs incorporating closed-loop feedback were performed, in which the fuel delivery schedule was adjusted based on real-time sensing of engine pressure data. The issues addressed during these runs included thermal effects on the boundary layer entering the engine, dynamic-pressure effects, angle-of-attack effects, data repeatability, effects of boundary-layer trips, and sideslip effects.

\section{Subsystem Verification and Validation}

The following subsections provide a description of subsystems incorporated in the HXFE/VFS model that are identical, or nearly identical to the corresponding $\mathrm{X}-43$ subsystems.

\section{Boundary-Layer Trips}

The first forebody compression surface on the VFS (and X-43) contains a slot to accommodate a set of boundary-layer trip devices (see Fig. 3). These trips are used in flight to ensure that a fully turbulent flow enters the engine inlet so as to improve inlet operability margin. ${ }^{6}$ Three different configurations were tested: no trips, the preliminary Mach 7 trips, and the final Mach 7 flight trips. The difference between the two trip designs (Figure 5) is that the trailing edges of the flight trips are truncated. Although the trips are not necessarily required for testing in the 8-Ft. HTT (the freestream turbulence level of the facility flow is much higher than in the atmosphere), they were incorporated and their effects were addressed for a more complete representation of the flight vehicle. Results on the use of these trips (Figure 6) show pitot pressure surveys at the centerline of the model just upstream of the cowl leading edge at the target flight condition. No significant difference in the pitot profiles is observed between the two types of boundary-layer trip designs. Furthermore, there is only a small increase in pitot pressure with no trips installed, indicating a small decrease in boundary-layer height. However, the boundary layer was turbulent for all runs, as previously mentioned.

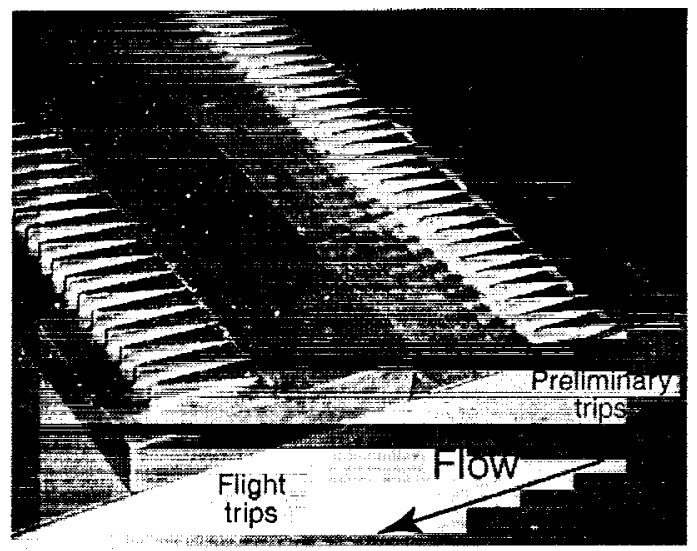

Figure 5. Comparison of forebody boundary-layer trips.

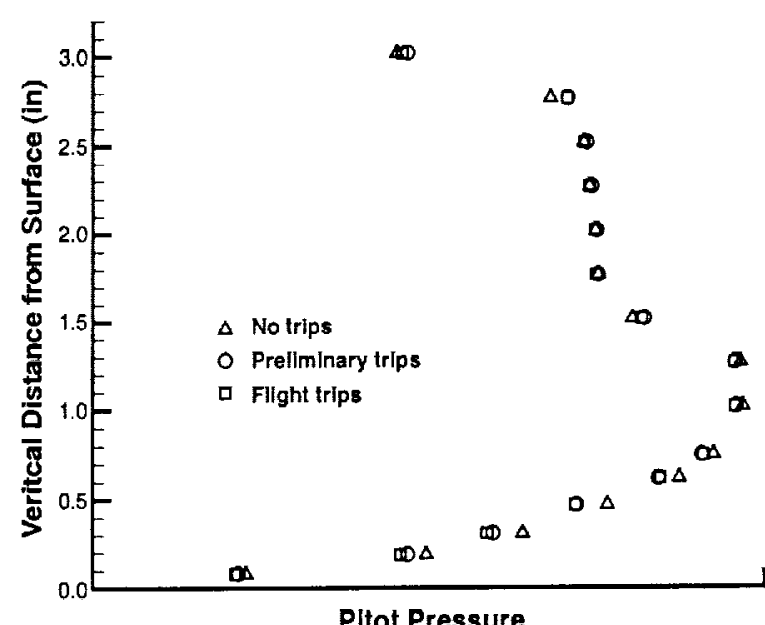

Figure 6. Effect of boundary-layer trips on centerline pitot pressure rake data just upstream of the cowl leading edge, $M_{\infty}=6.92, q_{\infty}=1000$ psf, $\alpha=2^{\circ}$. 


\section{AETB-12 TPS Tiles}

For the first ten runs of the HXFE/VFS test, two panels of Alumina-Enhanced Thermal Barrier (AETB-12) thermal protection system (TPS) tiles comprised the second and third forebody ramps (see Fig. 3). This is the same material that covers a majority of the X-43 airframe. A photograph of the AETB-12 TPS tile as tested is shown in Figure 7. The following results were realized during these runs: (1) the AETB-12 tiles withstood multiple exposures to the flight-like, high aerothermal loads with no degradation, (2) pre-test flight-like tile repairs were successfully performed and the repaired tiles also withstood flight-like aerothermal loads, and (3) flight-like installation of and data acquisition from pressure taps and thermocouples in the AETB-12 tiles were verified.

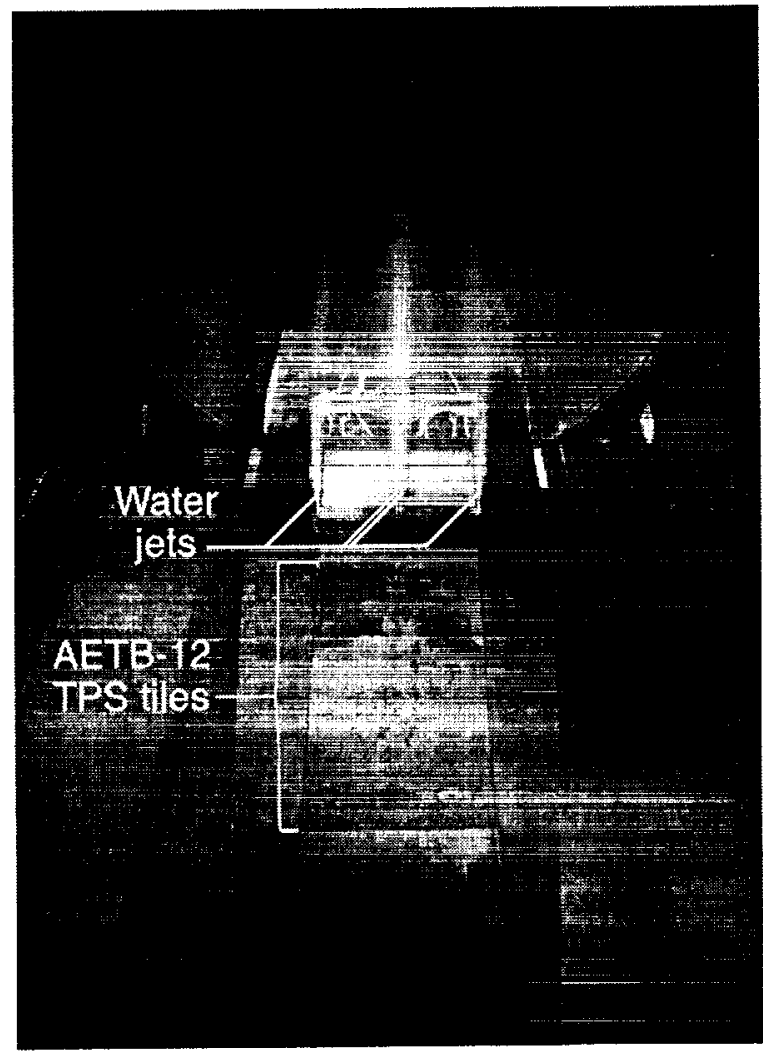

Figure 7. HXFE/VFS during run showing water jets and AETB-12 TPS tiles (view looking aft from above).

\section{Engine Integrity}

The HXFE, including body surface, sidewall, cowl, and fuel injectors was fabricated from Glidcop®, a copper alloy that is dispersion strengthened with ultrafine aluminum oxide particles. This yields a metal that possesses high strength at elevated temperatures and retains high thermal conductivity. Some internal surfaces were coated with a layer of zirconia TPS to provide a thermal barrier for the Glidcop $\circledast$ in highheating areas. Following fourteen unfueled runs and forty fueled runs, the structural integrity of the engine and the condition of the internal surfaces were nearly the same as prior to testing. The only difference was that a layer of silicon dioxide (a by-product of using silane for ignition) was usually deposited in the engine that required manual removal between runs. Even though this engine was required to be tested only once (in flight), it handled the rigorous ground test series without any problems.

The engine contained both static and dynamic seals to control the flow between parts. The static seals consisted of ceramic braided rope and were designed to have leak rates of less than 0.20 SCFM for each inch of seal material. The dynamic seals wiping between the engine cowl door and sidewall were made of 1/8-in. square braided ceramic carbon-fiber rope with a split inconel tube that act as a linear spring to keep the seal material in place. This design functioned well for two unfueled and five fueled runs; however, the first time the engine unstarted during a run at flight dynamic pressure, the seal material on the port side was dislodged. (Subsequently, a non-flight repair of both the port and starboard seals was performed to allow testing to continue.) The implications for flight risk are minimal because the engine will only see one thermal cycle during flight, and, additionally, there is logic built into the propulsion subsystem control (see next main section) to keep the engine from unstarting due to overfueling.

\section{Cowl and Sidewall Leading-Edge Water Cooling}

The HXFE utilized sidewall- and cowl-leading edge water-cooling passages identical to those in the X-43 flight engines. This subsystem during flight cools these regions of significant aerodynamic heating both during ascent and scramjet operation. Excessive heating could result in leading-edge deformation (altering the captured flowfield) or thermal expansion (causing the moving cowl door to seize). Water is delivered to three openloop cooling paths (see Figure 4) that route the coolant overboard through four small holes on external surfaces to the flowpath at the pressure and mass-flow rate expected in flight. Figure 7 shows the top view of the water jets exiting the HXFE during a tunnel run. No problems were encountered with the water-cooling subsystem during ground testing, and flight-like levels of pressure and mass-flow rate were realized; thus, verifying the design of this subsystem.

\section{Cowl Actuation and Inlet Starting}

For the X-43 flight tests, the engine will be closed during ascent to protect internal engine components; therefore, a mechanical actuation system was designed to open the cowl door and establish flow in (start) the 
inlet. There was a minor concern of inlet starting during the cowl opening sequence because of boundary-layer effects, internal contraction ratio effects, and cowlopening speed. The mechanical nature of the actuation design was fully replicated for HXFE/VFS testing. This design (shown in Figure 8) consists of a linear electromechanical actuator motor and controller that rotates a torque tube connected with cams to connecting links that are attached through the engine sidewalls to the cowl door. During initial testing of the final Mach 7 Hyper-X scramjet flowpath on a partial-width engine prior to the HXFE/VFS test, a similar cowl-actuation system was employed. Two slider blocks that are flush with the internal engine sidewalls moved with the connecting links and allowed for their proper freedom of movement. These sliders were made out of the same engine material to very small tolerances. Thermal growth and the use of similar metal resulted in galling of the sliders, which were then redesigned with increased clearances and coated with a thin layer of chrome. HXFE/VFS testing verified the successful redesign of the sliders, which had the potential of preventing the cowl door from opening during flight operation. The cowl door was actuated 355 times under no aerodynamic load (primarily during engine internal inspection and pre-run preparation) and 52 times under Mach 7 aerothermodynamic loads (during testing). For all cases, the cowl successfully actuated. This test allowed for the assessment of the actuation mechanism and understanding of the specifications for the actuator settings (speed and torque levels) required for flight.

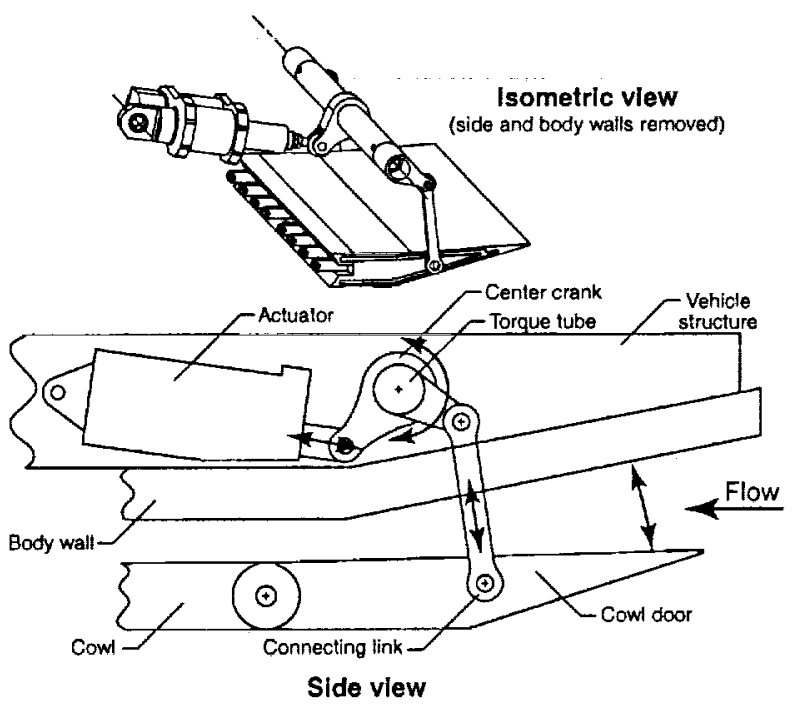

Figure 8. HXFE cowl actuation system schematic.
The effects of cowl actuation rate on engine inlet starting and flowfield establishment were investigated by actuating the cowl at flight rate (less than 0.5 seconds from cowl door closed to open) and at 1/4-flight rate. No problems were encountered with inlet starting in either case, and no differences were seen in the inlet flow structure.

The last run performed during this test series addressed the issue of cowl-door heating during its ascent on the booster to the Mach 7, 95,000-ft altitude, test point. The objective of the run was to approximate the cumulative heat load during ascent and, among other things, verify cowl-door actuation. Based on thermal analysis, subjecting the engine to about 25 seconds of Mach 7 flow in the 8-Ft. HTT at a dynamic pressure of $1230 \mathrm{psf}$ approximates the heating load that the engine will encounter during flight from launch-vehicle release to booster separation. The model was in the test flow for 26 seconds before the cowl door was commanded open. The cowl door actuated to the full-open position in 0.41 seconds with nominal torque outputs from the cowl actuator controller and yielded proper inlet flow establishment.

\section{Wing-Gap Heating}

The all-moving horizontal wings that provide pitch and roll control for the X-43 are attached to spindles that penetrate the vehicle airframe and are positioned by electromechanical actuators. A small gap exists between the wing root and the vertical face of the airframe. Gap heating at hypersonic speeds has been addressed for a variety of gap configurations, but no data is readily available for longitudinal wing gaps like those on X-43. A set of wing stubs (truncated at the midspan) were fabricated and a set of thermocouples were positioned on the airframe surface adjacent to the wing root to acquire temperature time history data to study the heating phenomenology for this type of gap. Three different gap sizes were studied: no gap, flight gap, and twice flight gap; data were also acquired with no wing stubs present as a baseline condition.

A comparison of the chordwise variation in the ratio of heating rates along the wing chord with respect to the no-wing results is shown in Figure 9. ${ }^{7}$ The preliminary data indicate that heating for the flight gap is less than 1.2 times the heating with no wing, except for just upstream of the spindle where the ratio increases to 1.3. At twice the flight gap, the heating is generally the same for the first half of the chord, yet increases in excess of two times the no-wing heating values are seen upstream of the spindle. This verified the thermal analysis applied to the $\mathrm{X}-43$ structural design in this area. 


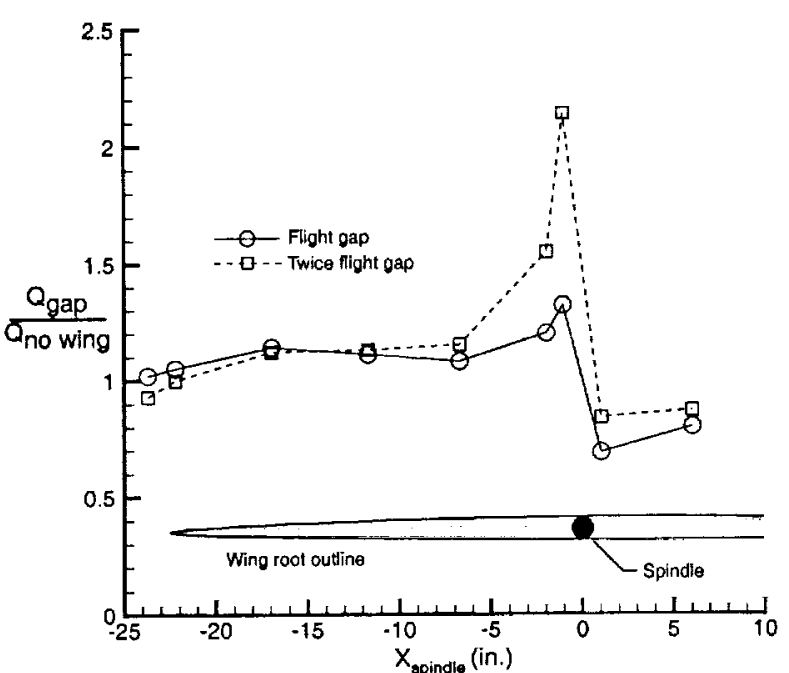

Figure 9. Effect of wing gap on gap heating, $M_{\infty}=6.92$, $q_{\infty}=1000$ psf, $\alpha=2^{\circ}$.

\section{Propulsion Subsystem Control Development.} Verification and Validation

To achieve the Hyper- $X$ flight test objectives of accelerating the $\mathrm{X}-43$ under controlled autonomous free flight, closed-loop control of the engine and engine systems is required. Propulsion Subsystem Control (PSC) software and hardware were designed and tested to provide engine-inlet cowl-door control and engine ignitor and fuel flow-rate control. The HXFE/VFS test in the 8-Ft. HTT provided several unique elements to the overall development, verification, and validation of the PSC flight software and engine and fluid systems hardware. The overall pre-flight effort consisted of multiple modeling, simulation, and test elements integrated to provide a comprehensive verification and validation of the complete system. Figure 10 illustrates the process used to ensure that each hardware and software element was thoroughly tested. Although no one test captured the complete system and flight environment, overlapping tests in the integrated verification and validation plan ensured comprehensive testing, including all interfaces.

The PSC development and simulation environment provided an isolated computer simulation used to develop and perform unit testing on the PSC control laws; however during these tests, the control laws were neither integrated with the complete flight software nor resident on the flight computer. PSC flight software performance was verified as part of the complete Operational Flight Program (OFP) during Hardware-inthe-Loop (HIL) testing. During HIL testing the flight software was hosted on the Flight Management Unit (FMU) while all other vehicle systems and flight conditions were simulated on the simulation bench. This approach allowed extensive testing of the software over a wide spectrum of possible conditions and scenarios without putting unnecessary cycles on vehicle systems hardware. Fluid systems performance verification tests provided complete stand alone flight fluid systems hardware verification of the integrated fluid systems; however, these tests were not run closedloop with the PSC flight software hosted on the FMU. This was accomplished during Vehicle-in-the-Loop (VIL) testing in which the complete OFP hosted on the FMU interfaced with the complete fluid systems while a nominal flight scenario was simulated on the simulation bench. Hence, the entire system had been tested with the exception of scramjet engine operation running in closed-loop with the propulsion control laws. The HXFE/VFS test provided this final element with the HXFE operation in a wind-tunnel simulated flight environment. In these tests flight-type fluid and cowl actuation systems controlled by a wind-tunnel specific version of the PSC flight software hosted on a bench control system provided a closed-loop system with scramjet operation. The following subsections discuss the specific requirements and objectives for these tests in detail.

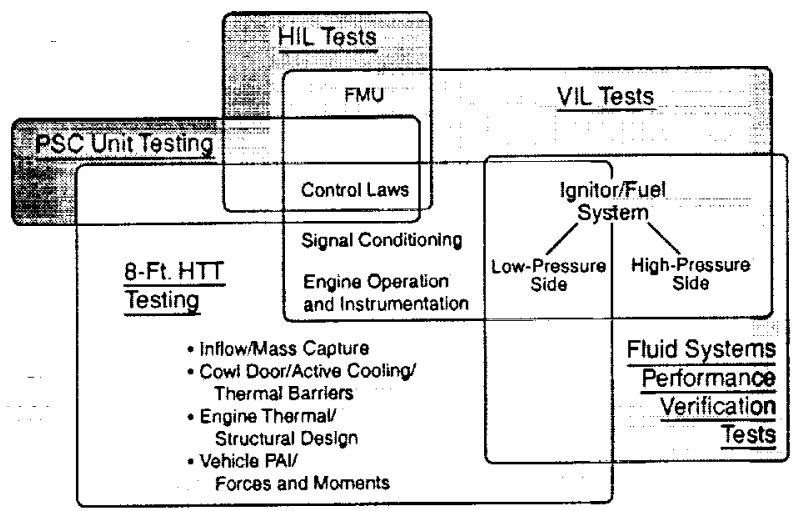

Figure 10. Propulsion subsystem control development, verification, and validation schematic.

Hardware and Software Requirements

Control System. A bench control system running the Matlab® Simulink® environment used for flight software development was used to generate a windtunnel specific version of the flight control laws in which the control loops were identical to those imbedded in the flight software, but the interfaces were modified for wind-tunnel application. A top-level schematic representing these control loops and the required sensed parameters is shown in Figure 11. The ignitor and fuel schedule is established based on the sensed flight condition and commanded vehicle attitude and is then adjusted based on engine flowpath pressure feedback and vehicle acceleration feedback. The ignitor and fuel mass-flow rates are then established through 
closed-loop mass flow control as indicated in the figure. All signal conditioning, sample rates, and control-loop rates were matched to the flight systems. Figure 12 shows the compact nature of the control system, utilized in HXFE/VFS testing to simulate the X-43 PSC functions.

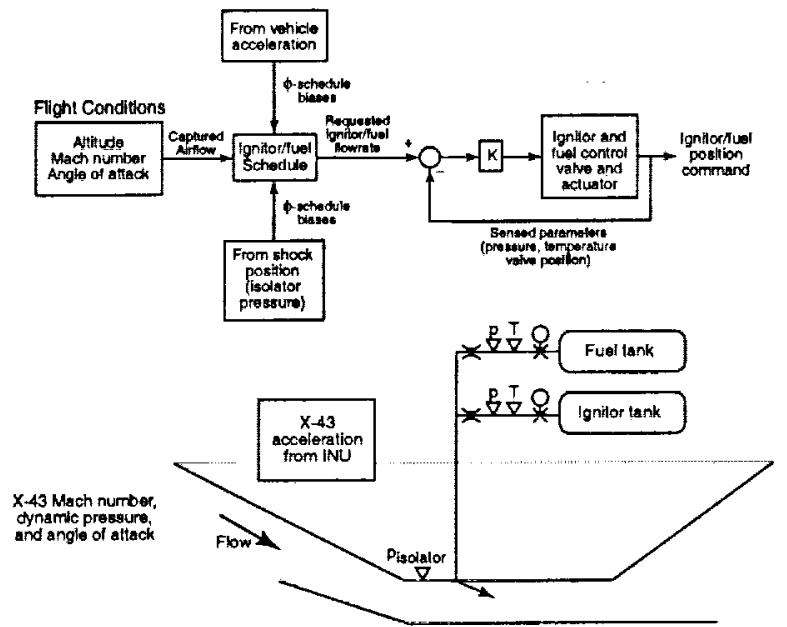

Figure 11. Ignitor and fuel control block diagram and schematic drawing.

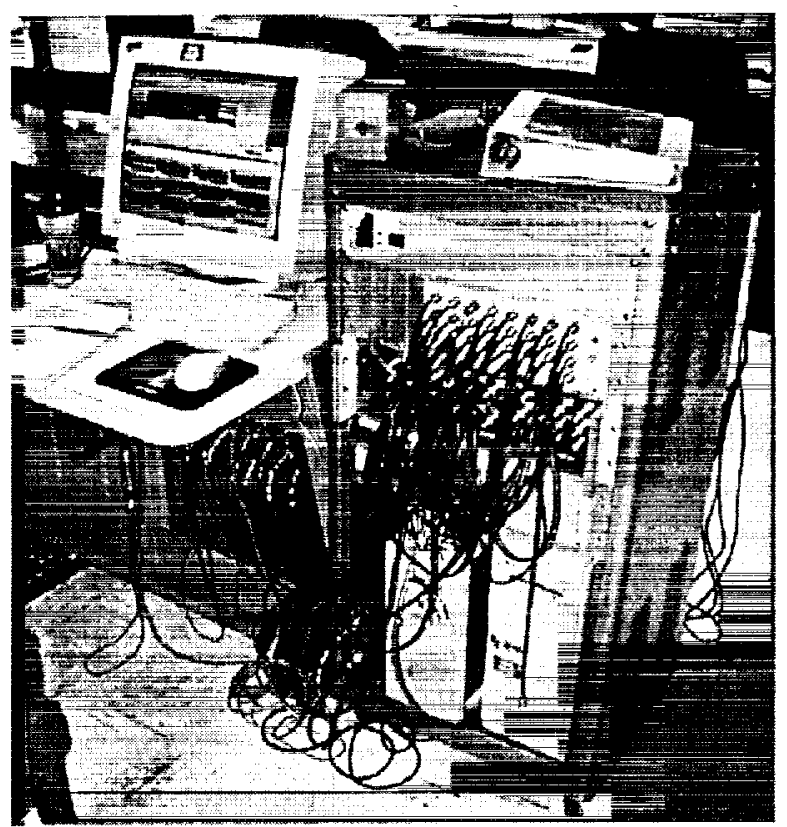

Figure 12. PSC computer used during HXFE/VFS testing.

Ignitor and Fuel System. In order to verify the inner-loops controlling the ignitor and fuel mass flow rates, the fluid system plumbing (including fittings, line lengths and diameters), control valves, venturi flow meters, and sensors had to be accurately simulated. To achieve this, flight-type valves with similar mechanical and fluid dynamic characteristics were used. Figure 13 shows the pedestal internal cavity just below the model that contains the closely-coupled ignitor and fuel control valves, actuators, and venturi flow meters, as well as the ignitor/fuel mixing manifold that feeds the bodyside and cowlside fuel-injectors via tubing of flight-like length. Flight fuel delivery pressures and flight-like components downstream of the control valves, including flight fuel injectors, were utilized, and flight-identical instrumentation was used throughout the fluid systems.

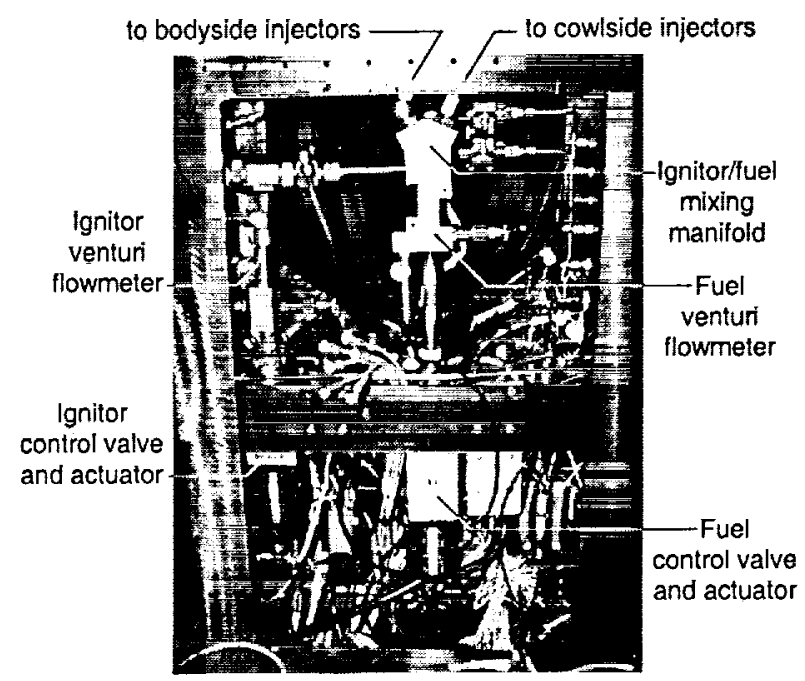

Figure 13. Flight-like ignitor and fuel system details (located in the pedestal just below the model).

Elowpath Sensors. Multiple flowpath pressure sensors were used for feedback as part of the PSC for engine-unstart prevention. The sensors and their installation were identical to those in the X-43 as shown in the photograph of the HXFE in Fig. 4.

\section{Control Law Verification}

Ignition and Transition to Hydrogen Fuel. X-43 packaging constraints resulted in a limited supply of both ignitor (mixture of $20 \%$ molar silane in hydrogen) and hydrogen fuel, which subsequently resulted in a limited duration test window in which to design an ignitor and fuel sequence to meet the test objectives. The ignitor and fuel flow rate profiles required for ignition, transition to hydrogen-only fueling, and to achieve vehicle acceleration were developed and verified during these tests. This was achieved while meeting the additional requirements of acquiring steady-state engine/vehicle data and preventing engine unstart due to over-fueling. The ability to perform these tests on the flight hardware at simulated flight conditions provided significant risk reduction to the flight test.

Engine-Unstart Prevention. The Hyper-X flight project was aided by concurrent engineering in many key areas. While the HXFE/VFS test provided the first scramjet data on the full-width, full-length enginel vehicle propulsion flowpath, the propulsion system 
hardware, instrumentation, and control system software architecture was already in place. The final flight control laws were developed and verified within this context. One of the most important features of PSC, whose design was finalized and subsequently verified as part of these tests, is to prevent engine unstart during the flight experiment, but still achieve vehicle acceleration. The control logic used to achieve this is presented in Figure 14.

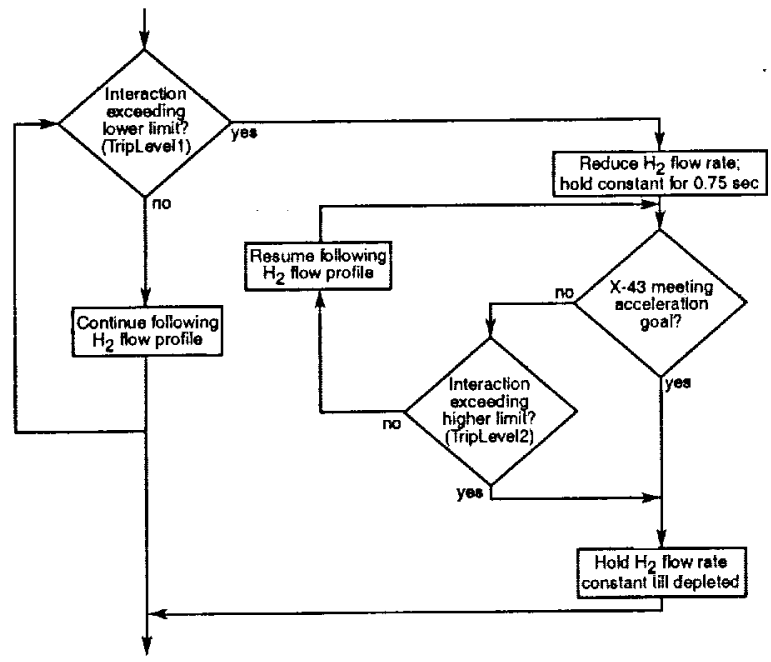

Figure 14. Fuel control block diagram for unstart avoidance and meeting program objective.

Once engine ignition has been achieved and the engine and vehicle have stabilized for acquisition of steady data, fuel flow is increased and this logic becomes active. If the engine flowpath pressures indicate that combustor-isolator interaction is occurring, and simultaneously exceeding a pre-set lower limit (TripLevel1), then the pre-programmed fuel schedule is interrupted. The fuel flow is reduced and held constant for 0.75 seconds, after which the PSC evaluates vehicle acceleration based on inputs from the inertial navigation unit (INU). If the pre-set acceleration goal has been met, the fuel flow is held constant until a controlled flow-rate ramp down is commanded as the fuel is depleted; however, if the pre-set acceleration goal has not been met, the level of combustor-isolator interaction is evaluated based on a pre-set higher limit (TripLevel2). Additionally, if this limit is exceeded the fuel flow is held constant until the controlled ramp down is reached. If the acceleration goal has not been met and combustorisolator interaction is lower than the higher limit, then the fuel ramp-up is resumed. The intent of this logic sequence is to maximize the probability of achieving the acceleration goal while concurrently guarding against engine unstart. The two-level interaction criteria balances the risk of inlet unstart against the importance of attaining the acceleration goal. The control laws implementing this logic were finalized and verified during these tests and data were acquired for the basis of setting the TripLevell and TripLevel 2 constants used in flight.

\section{Vehicle Performance}

Because of the integrated nature of scramjetpowered configurations, the basic aerodynamic characteristics of this vehicle are strongly coupled with the propulsion system effects. Prior to HXFE/VFS testing, estimates of the longitudinal force and moment data were determined to develop the vehicle performance, stability, and control characteristics for the X-43 flight control laws. ${ }^{8}$ These estimates were developed from a combination of aerodynamic windtunnel testing of the closed-cowl configuration and the Hyper-X methodology of using analytical and computational results to estimate the cowl opening and powered effects. ${ }^{9}$ The HXFE/VFS was tested at the offnominal angles of attack of zero and four degrees to complement the data taken at the nominal flight angle of attack of two degrees. This allowed better examination of the design space from which the pre-flight performance database was generated. Furthermore, excursions of one and three degrees in sideslip angle were addressed. The concern was that, at hypersonic speeds, even a minor perturbation in sideslip angle from zero might have an adverse effect on vehicle performance. This is due to an expansion fan (created on the windward sidewall leading edge) and a shock wave (created on the leeward sidewall leading edge) both being processed by the inlet.

Figure 15 presents a comparison of lift, drag, and pitching moment coefficients (with no horizontal tail deflection) for the cowl closed, cowl-open unfueled, and cowl-open fueled conditions. Data shown are for comparative purposes. The database estimates, shown by the solid symbols, were developed by applying the computed cowl-opening and power-on increments to the experimentally derived aerodynamic database for the cowl-closed configuration. The increments included in the figure are the differences in the force and moment values between the unfueled cowl-closed and cowl-open conditions and between the unfueled and fueled (at $\phi=$ 1.2) cowl-open conditions. The force and moment increments acquired from the 8-Ft. HTT FMS are applied to the same cowl-closed aerodynamic wind tunnel data to create the HXFE/VFS data and are depicted by the open symbols.

In general, there is very good agreement between the estimated and measured increments. Where the comparisons differ the most $\left(C_{D}\right.$ fueled at $\left.\alpha=4^{\circ}\right)$, the experimental results actually show improved performance (less drag, i.e., more thrust). These results 
are significant because they build confidence in the Hyper-X pre-flight database methodology for this configuration at conditions near the target scramjet test point, as well as demonstrate that there is a significant effect of forebody and aftbody pressurization that affects both the aero-propulsive loads and the pitchingmoment values and, thus, the ability to trim the vehicle. Since associated trim-drag penalties have a significant impact on net vehicle thrust, the ability to accurately estimate (and measure) this component in powered flowpath analysis and testing is important. Also included in the figure are the results for the two nonzero sideslip runs at $\alpha=2^{\circ}$. Results indicate that there is little, if any, degradation in aero-propulsive performance at these conditions even though the inlet possesses an asymmetric pressure field.

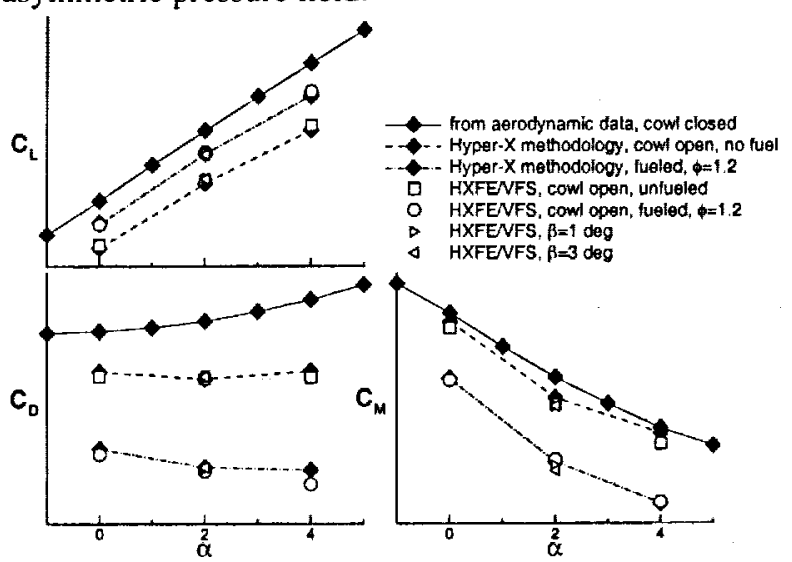

Figure 15. X-43 force and moment data versus $\alpha$, $\mathrm{M}_{\infty}=6.92, \mathrm{q}_{\infty}=1000 \mathrm{psf}$

\section{Propulsion-Airframe Integration}

One of the more important, yet often neglected, issues that needs to be addressed in a hypersonic airbreathing propulsion vehicle design effort is propulsionairframe integration (PAI). For this class of vehicle, PAI addresses the integration of a dual-mode scramjet to a slender-body airframe capable of hypersonic speeds, as well as the aero-propulsive interactions of the highlycoupled internal and external flowfields. These interactions include inlet spillage, exhaust pluming and the resulting impact on lifting and control surfaces, and engine/airframe forces and moments.

The test of the HXFE/VFS provided a unique opportunity to address PAI since the test article comprises the key elements needed to assess the interactions between the scramjet (HXFE) and a realistic airframe surface (VFS). The forces and moments issue was discussed in the previous section. Samples of the external flowfield and exhaust pluming results follow.

\section{Schlieren Experimental Elowfield Results.}

Figure 16 depicts composite images of the flow patterns emanating from the flowpath surface of the HXFE/VFS during the three distinct stages in the scramjet test. For all runs, the shock structure upstream of the cowl leading edge was quite stable, and included the bow shock, weak waves from the boundary-layer trips, and additional compression emanating at each of the two forebody ramps. These shocks are part of the overall compression process required to obtain the

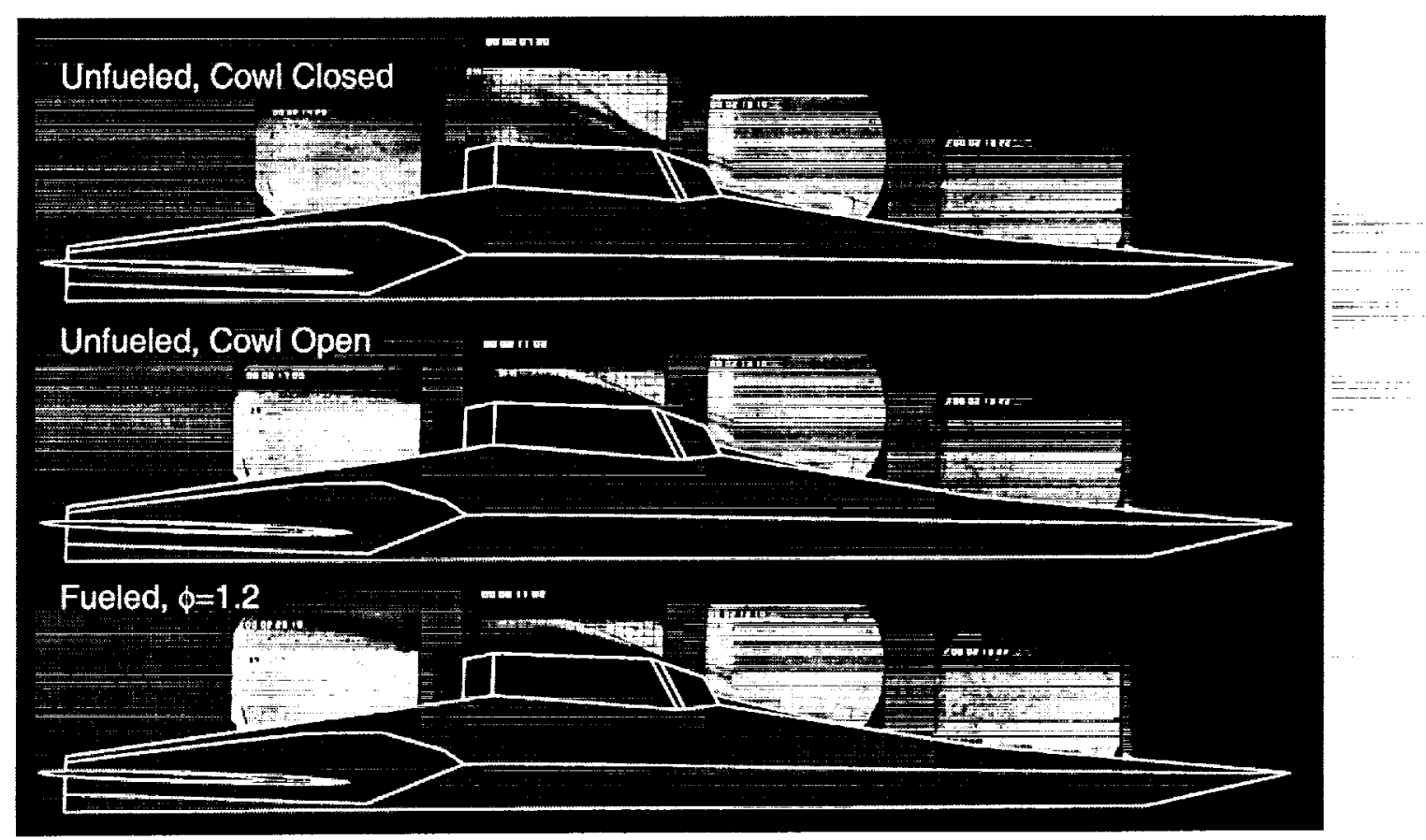

Figure 16. Comparison of composite schlieren images for distinct scramjet test events, $M_{\infty}=6.92, q_{\infty}=1000 \mathrm{psf}, \alpha=2^{\circ}$. 
desired pressure levels entering the combustor. A strong shock off the cowl leading edge is seen above the engine (as seen in the figure) in the cowl-closed configuration, and there is indication of significant shear flows and a separation zone that occupies the first third of the aftbody behind the cowl trailing edge. When the cowl door is opened, the shock generated off the cowl leading edge changes, and the shear layer downstream of the cowl trailing edge is seen by the alignment of the cooling water jets (dark region) above the aftbody surface. During fueled operation, the plume caused by the increased engine pressure levels due to combustion has shifted the shear layer farther away from the aftbody surface. Waves seen downstream of the cowl-trailing edge result from the internal nozzle geometry.

SiO2 Deposits and Oil-Flow Results

Figure 17 indicates the lateral extent of the plume expansion on the aftbody, evidenced in the deposition of silicon dioxide $\left(\mathrm{SiO}_{2}\right.$, a white particulate and by-product of the reaction of the silane/hydrogen ignitor gas combustion process). The plume is seen to extend laterally outward beyond the cusp line that defines the aftbody nozzle surface. Vortical flow exists with a separation/reattachment region shown, as evidenced by the lack of $\mathrm{SiO}_{2}$ just outside, and nearly parallel to, the cusp lines.

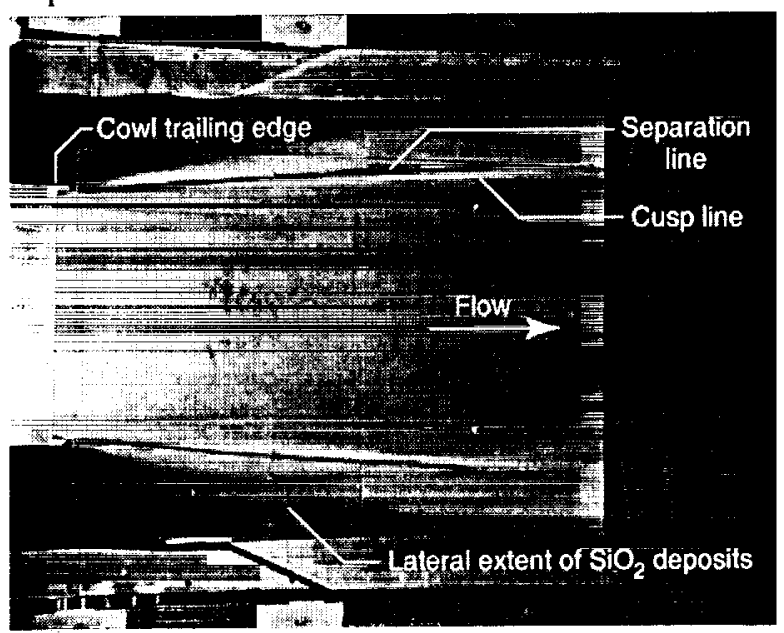

Figure 17. $\mathrm{SiO}_{2}$ deposits on VFS aftbody following a fueled run, $M_{\infty}=6.92, q_{\infty}=1000 \mathrm{psf}, \alpha=2^{\circ}$.

Aftbody oil-flow patterns (Figure 18) also indicate the symmetric nature of the powered exhaust flow. The flow is symmetrically aligned relative to the vehicle centerline, and lateral expansion is visible as the plume expands into the aftbody nozzle (including just downstream of the cowl trailing edge). In addition, no $\mathrm{SiO}_{2}$ deposits were observed on the wing-stub surfaces, and there were no discernible differences in the wingstub, oil-flow patterns for unpowered and powered runs. This finding is important because it indicates that proper wing placement was verified in that the exhaust plume, fueling levels, and other engine operability factors did not significantly affect control surface effectiveness; thus, validating the aero-propulsive database, which assumed no power-on effects on the control surfaces.

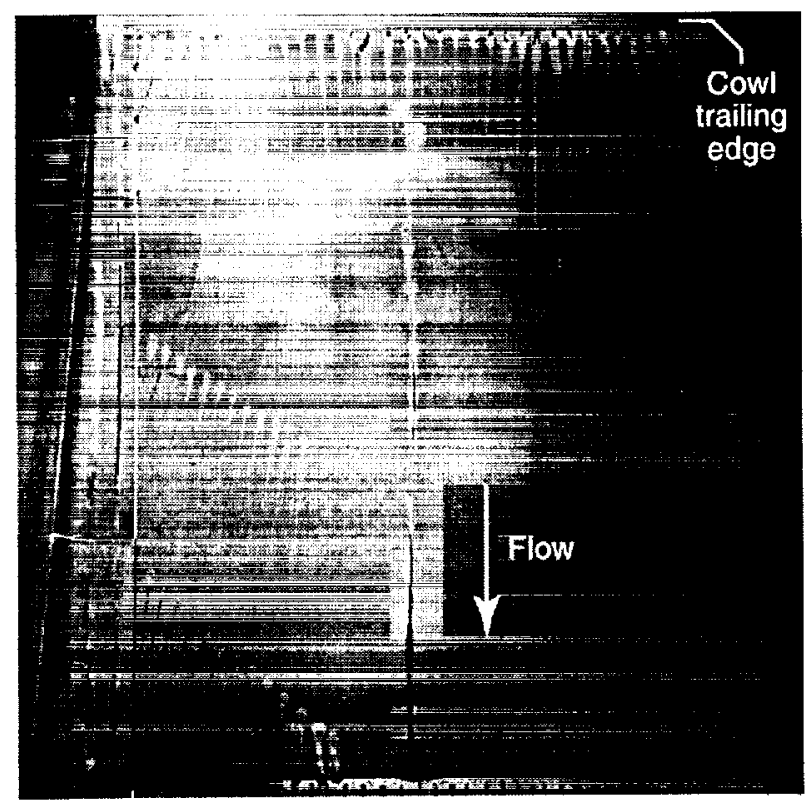

Figure 18. VFS aftbody oil-flow patterns following a fueled run, $M_{\infty}=6.92, q_{\infty}=1000 \mathrm{psf}, \alpha=2^{\circ}$.

\section{Aftbody Pressure Distributions}

The effects of cowl opening and fueling are observed in the aftbody pressure distributions (Figures 19 and 20). Pressure-difference contours (in coefficient form) were created from the discrete surface-pressure data (identified by the small circles on the figures) such that the difference in the pressure is calculated in the following manner:

$$
\begin{aligned}
& \Delta C_{p, \text { cowl }}=\left(C_{p, \text { cowl-open }}-C_{p, \text { cowl-closed }}\right) \\
& \Delta C_{p, \text { fuel }}=\left(C_{p, \phi>0}-C_{p, \phi=0}\right)
\end{aligned}
$$

Figure 19 presents $\Delta C_{p, \text { cowl }}$ data for two different runs, both at the nominal flight Mach number, angle of attack, and dynamic pressure. The difference is that Fig. $19 \mathrm{a}$ is at $\beta=0^{\circ}$ and Fig. $19 \mathrm{~b}$ is at $\beta=3^{\circ}$. For reference, the cowl trailing edge is located at the left middle of each contour, and the wing stubs and ventral fins are shown for clarity. When the cowl opens, the aftbody pressures react to the processing of the flow through the engine in a very symmetric sense for $\beta=0^{\circ}$, but very asymmetrically for $\beta=3^{\circ}$, albeit at about the same inflow pressure level. The shock and expansion waves emanating from the cowl sidewall leading edges are still evident in the aftbody flowfield. The slight increase in windward chine pressures near the ventral fin is also observed. When the engine is operating at the flight- 
designed hydrogen fuel level, $\Delta \mathrm{C}_{\mathrm{p}}$, fuel contours (Figure 20 ) indicate that the external nozzle flowfield is very similar for both sideslip angles, although the slight increase in chine pressures near the ventral fins indicates that measurable lateral expansion is occurring under both powered conditions. Furthermore, differences in the pressures on the chines is still evident for the $\beta=3^{\circ}$ run.
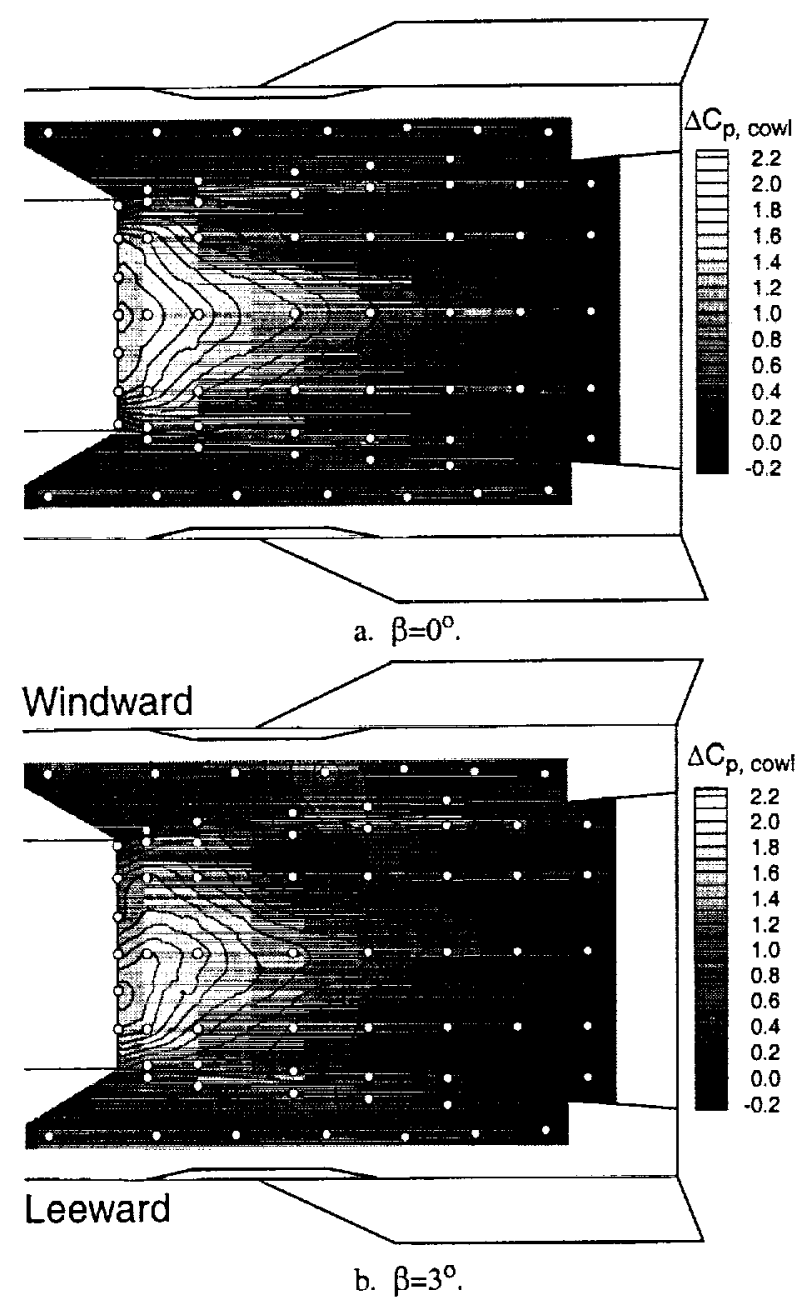

Figure 19. Aftbody pressure coefficient increase due to cowl opening, $M_{\infty}=6.92, q_{\infty}=1000$ psf, $\alpha=2^{\circ}$.

\section{Non-Elight Verification}

Two significant studies were performed during this test that, although not specifically impacting the X-43 Mach 7 flights, are significant in the future development of hypersonic air-breathing propulsion vehicles. One of these is related to propulsion control and the other is related to vehicle candidate materials and their effect on engine performance.
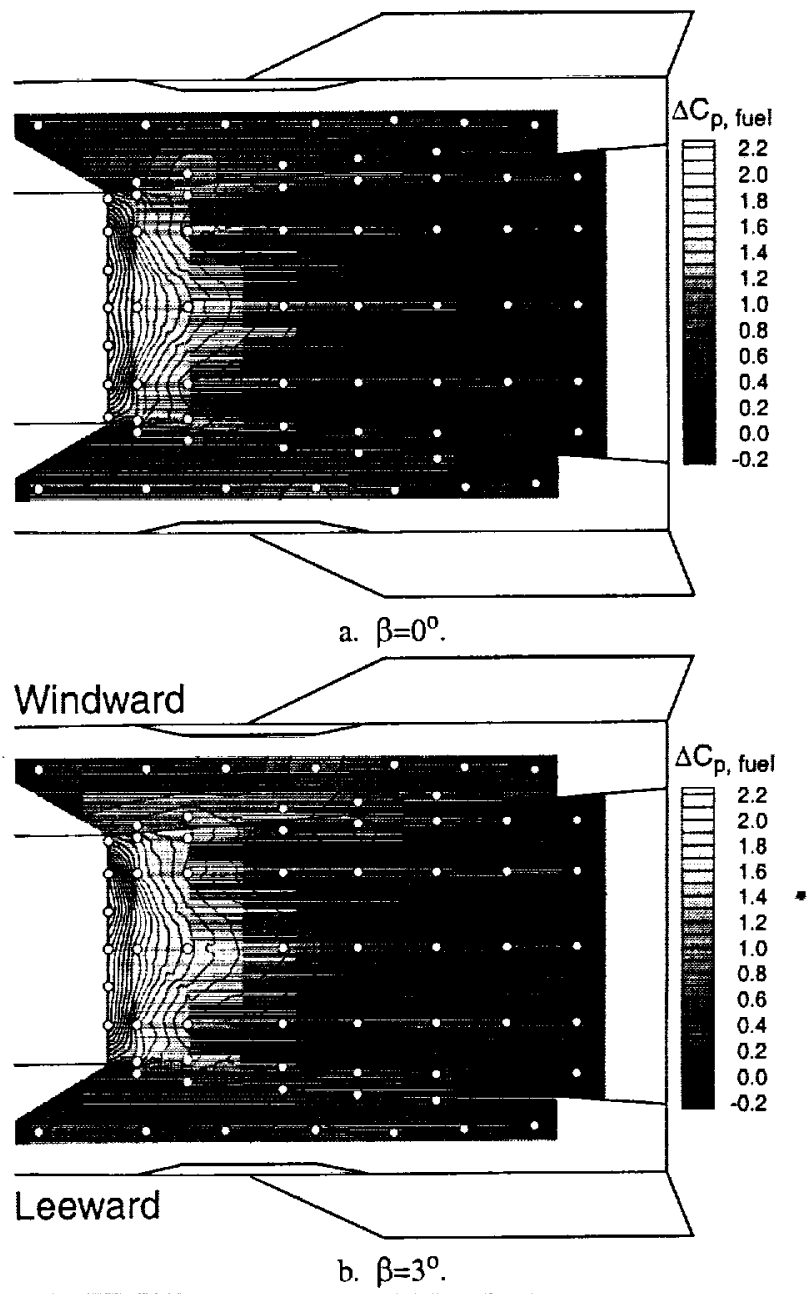

Figure 20. Aftbody pressure coefficient increase due to fueling, $M_{\infty}=6.92, q_{\infty}=1000 \mathrm{psf}, \alpha=2^{\circ}$.

\section{Engine UnstartRestart Capability}

During the combustion process in a dual-mode scramjet, high pressure develops in the combustor that, with increased fueling, back-pressures the isolator and ultimately can "unstart" the inlet (analogous to compressor stall in a turbojet). Although engine controls can be used to throttle the engine and prevent unstart, it is imperative to demonstrate the ability to "restart" the inlet and combustion process. The PSC software used in HXFE/VFS testing was sufficiently robust to allow, with minimal effort, the ability to test this capability. One successful run demonstrated this by purposely causing the HXFE inlet to unstart (via excess fueling), followed by rapidly throttling-down the fuel, restarting the inlet flow by actuating the cowl door closed then open, and subsequently re-igniting the engine. The entire restart process was achieved in 1.76 seconds, and the data indicate that it could have been 
achieved significantly faster. (Note that no effort was made to optimize the process, only to demonstrate feasibility.) In addition to demonstrating engine restart, the analysis of the force and moment data acquired during the unstart/restart process provides valuable insight into vehicle dynamics and is an important component of the ability to establish and maintain controlled hypersonic flight.

\section{Ablative TPS Effects}

The HXFE/VFS model was also employed to verify the use of a new lightweight ablative TPS developed by The Boeing Company. For two tunnel runs, the final forebody compression ramp (just before the HXFE cowl leading edge) and the first half of the external nozzle were replaced with TPS panels known as BLA-20 (see Figures 21 and 22, top). When the BLA-20 is subjected to heat, organic compounds within the TPS ablate, leaving a charred tile-like silica surface that maintains its geometric characteristics. The panels were thermally isolated from the surrounding copper external surfaces. The objectives of these runs were to determine if the out-gassing from the ablator affected engine performance and operability and to determine survivability of the TPS both ahead of and behind the engine. Overall, TPS survivability during the Mach 7

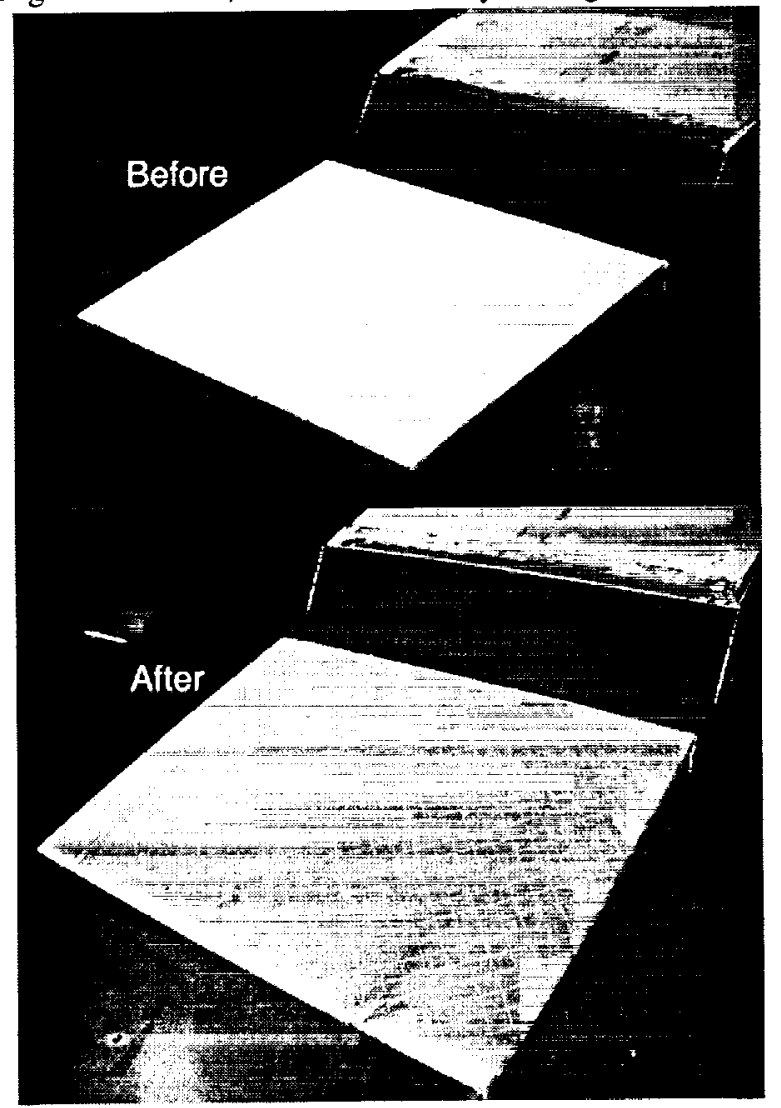

Figure 21. Comparison of pre-and post-run forebody BLA-20 TPS. 1000-psf dynamic pressure (both extremes for this TPS), 22-second run was very good; however, there was a modest amount of surface pitting, primarily of the forebody panel which appeared to be a combination of impact and crack bridging on the surface (as seen in the figures). Lap joints and a repair of simulated damage on the aftbody panel survived intact after each run. Temperature measurements acquired on the TPS/ substrate interface showed no appreciable temperature rise during the runs and a maximum soak-back temperature rise of $35 \mathrm{~F}^{\circ}$ was obtained on the forebody panel six minutes after the run. During the runs, the HXFE was fueled with an X-43 flight-like sequence that ramped hydrogen to the target fight fuel equivalence ratio. This is the first time this type of ablator material has been tested with an operating engine. The HXFE lit well for both runs and maintained robust combustion throughout. The engine performance did not appear to be affected by the ablator out-gassing. The second run was the first time that this monolithic BLA-20 TPS was re-tested and provided data to address reusability of the TPS for non-expendable applications. The TPS panels were returned to The Boeing Company for measurement of mass loss, char density, and amount of recession.

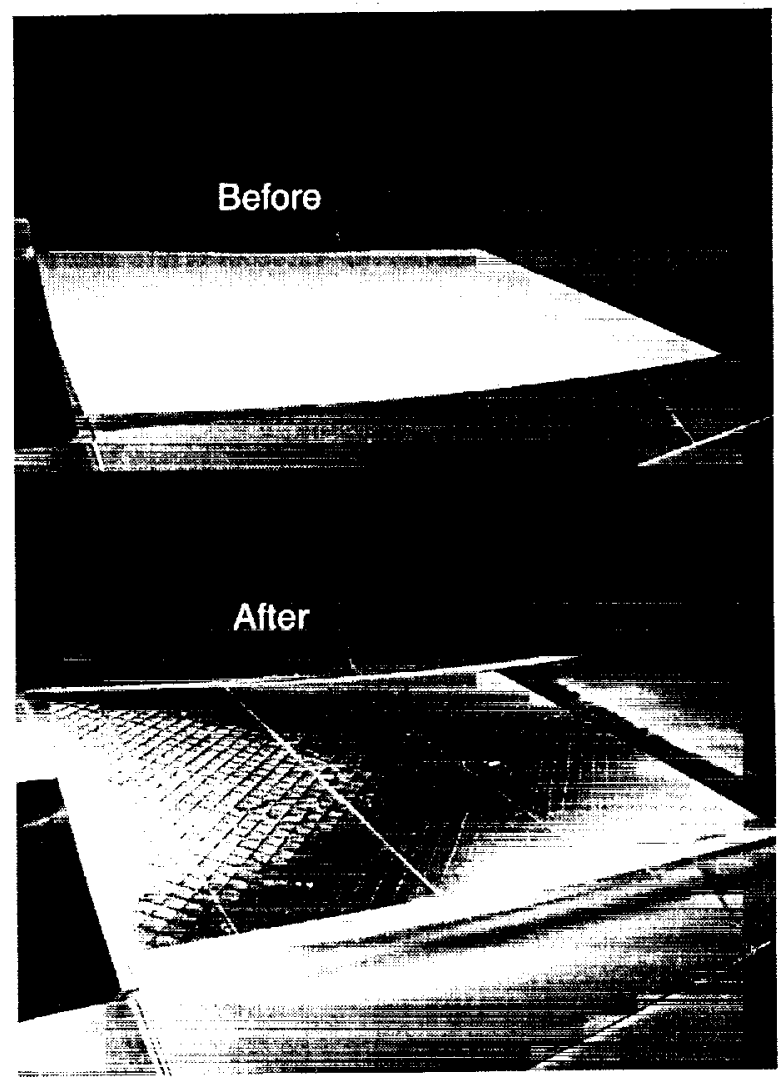

Figure 22. Comparison of pre-and post-run aftbody BLA-20 TPS 


\section{Summary}

This paper presents a description of, and supporting data on, the significance of the Hyper-X Flight Engine/ Vehicle Flowpath Simulator tests performed in the NASA Langley 8-Foot High Temperature Tunnel in support of risk reduction for the Mach 7 flights of the $\mathrm{X}-43$. Following a brief description of the facility, model, and test summary, the engine and flowpath subsystems that were verified and validated for flight were documented. These include the use of forebody boundary-layer trips, cowl actuation, water cooling of engine leading edges, engine structural integrity, wing gap heating, and propulsion subsystem control hardware and software. Following this, supporting data was presented which included vehicle performance and propulsion-airframe integration. Finally, a description of two efforts that constitute future scramjet-powered vehicle capabilities were presented; namely, the ability to restart the engine following an unstart and the use of ablative TPS tiles on the engine flowpath.

This test was unique in that it addressed many issues for the first time: (1) full airframe-integrated, scramjet-powered model test in a wind tunnel at flight conditions, (2) dual-mode scramjet flight control testing for an airframe-integrated scramjet-powered vehicle, (3) yaw-effect testing of a scramjet, (4) scramjet testing using ablative TPS tiles on the forebody and external nozzle, and (5) engine data to validate conventional scramjet module test techniques. In addition, this test program (1) provided propulsion performance and operability over a range of dynamic pressures and angles of attack, (2) validated the scramjet test article structure and functionality, (3) verified the powered aerodynamic database originally developed using aerodynamic models, CFD, and other analytical methods, and (4) was useful in quantifying the performance impact of partial-width versus full-scale testing.

\section{Acknowledgement}

This test demonstrated the outstanding capabilities of the 8-Foot High Temperature Tunnel to support largescale testing of hypersonic airbreathing propulsion systems. Facility operations were executed well; a thorough characterization of the tunnel test section flow field exists; and there was active participation by the staff to incorporate complex engine support hardware and software, acquire a significant quantity of quality model data, and handle real-time changes in test plans. The authors thank the 8-Ft. HTT staff for their dedication and hard work.

\section{References}

1. Rausch, V. L.: McClinton, C. R.; and Crawford, J. L.: "Hyper-X: Flight Validation of Hypersonic Airbreathing Propulsion." ISABE 97-7024, September 1997.

2. Rausch, V. L.; McClinton, C. R.; and Sitz, J. R.: "The Hyper-X Program Overview." ISABE 997213, September 1999.

3. Rock, K. E.; Voland, R. T.; Rogers, R. C.; and Huebner, L. D.: NASA's Hyper-X Scramjet Engine Ground Test Program." ISABE 99-7214, September 1999.

4. Huebner, L. D.; Rock, K. E.; Witte, D. W.; Ruf, E. G.; and Andrews, Jr., E. H.: "Hyper-X Engine Testing in the NASA Langley 8-Foot High Temperature Tunnel." AIAA 2000-3605, July 2000.

5. Hodge, J. S.; and Harvin, S. F.: "Test Capabilities and Recent Experiences in the NASA Langley 8Foot High Temperature Tunnel." AIAA 20002646, June 2000.

6. Berry, S. A.; Auslender, A. H., Dilley, A. D.; and Calleja, J. F.: "Hypersonic Boundary-Layer Trip Development for Hyper-X." AIAA 2000-4012, August 2000.

7. Daryabeigi, K.; and Huebner, L. D.: "Heating Rate Measurements on Hyper-X Wing Gap." Proposed NASA Technical Memorandum, Draft completed December 2000.

8. Engelund, W. C.; Holland, S. D.; Cockrell, Jr., C. E.; and Bittner, R. D.: "Propulsion System Airframe Integration Issues and Aerodynamic Database Development for the Hyper-X Research Vehicle." ISABE 99-7215, September 1999.

9. Cockrell, Jr., C. E.; Engelund, W. C.; Bittner, R. D.; Dilley, A. D.; and Jentink, T. N.: "Integrated AeroPropulsive CFD Methodology for the Hyper-X Flight Experiment." AIAA 2000-4010, August 2000 . 